\title{
Mesenchymal stromal cells from myelodysplastic and acute myeloid leukemia patients display in vitro reduced proliferative potential and similar capacity to support leukemia cell survival
}

Giulia Corradi, Carmen Baldazzi, Darina Očadlíková, Giovanni Marconi, Sarah Parisi, Nicoletta Testoni, Carlo Finelli, Michele Cavo, Antonio Curti ${ }^{\dagger}$ and Marilena Ciciarello ${ }^{* \dagger}$ (D)

\begin{abstract}
Background: Mesenchymal stromal cells (MSCS) are an essential element of the bone marrow (BM) microenvironment, playing a crucial function in regulating hematopoietic stem cell proliferation and differentiation. Recent findings have outlined a putative role for MSCs in hematological malignancy development. So far, conflicting results have been collected concerning MSC abnormalities in acute myeloid leukemia (AML) and myelodysplastic syndrome (MDS). In particular, a considerable amount of evidence has been accumulated strongly supporting a permissive role of MSCs in malignancy evolution to MDS, while a potentially causative or promoting function performed by MSCs in AML has not yet been fully clarified. Here, we compared MSCs isolated from healthy, MDS, and AML subjects to investigate MSC alterations and to emphasize putative common and/or diverse features.

Methods: We isolated and expanded MSCs from AML patients (AML-MSCS) and MDS patients (MDS-MSCS), and we analyzed and compared their phenotypic and functional properties with respect to each other and versus healthy donor-derived MSCS (HD-MSCS).

Results: We found that stable MSC cultures could be easily established from HD and MDS mononuclear BM-derived cells, while a substantial fraction (25\%) of AML patients failed to yield MSCs. Nevertheless, isolated MDS-MSCs and AMLMSCs, as well as HD-MSCs, contained the basic features of MSCs. Indeed, they displayed similar surface marker expression and efficient capacity to differentiate versus osteogenic and adipogenic lineage in vitro. We also proved that MDS-MSCs and AML-MSCs, analyzed by fluorescence in-situ hybridization, did not harbor leukemic cell cytogenetic abnormalities. Moreover, MDS-MSCs and AML-MSCs were similar in terms of ability to sustain AML cell viability and immune-regulatory capacity. However, we were also able to detect some differences between AML-MSCs and MDS-MSCs. Indeed, we found that the frequency of rescued MSCs was lower in the AML group than in the HD and MDS groups, suggesting that a reduced number of MSC precursors could inhabit AML BM. Instead, MDS-MSCs showed the lowest proliferative capacity, reflecting some intrinsic and particular defect.

(Continued on next page)
\end{abstract}

\footnotetext{
* Correspondence: marilena.ciciarello2@unibo.it

${ }^{+}$Antonio Curti and Marilena Ciciarello contributed equally to this work.

Department of Experimental, Diagnostic and Specialty Medicine, Institute of

Hematology "L. \& A. Seràgnoli", University of Bologna, Azienda

Ospedaliero-Universitaria Policlinico S. Orsola-Malpighi Bologna, Via

Massarenti 9, 40138 Bologna, Italy
}

(c) The Author(s). 2018 Open Access This article is distributed under the terms of the Creative Commons Attribution 4.0 International License (http://creativecommons.org/licenses/by/4.0/), which permits unrestricted use, distribution, and reproduction in any medium, provided you give appropriate credit to the original author(s) and the source, provide a link to the Creative Commons license, and indicate if changes were made. The Creative Commons Public Domain Dedication waiver (http://creativecommons.org/publicdomain/zero/1.0/) applies to the data made available in this article, unless otherwise stated. 
(Continued from previous page)

Conclusions: Overall, our results elucidated that MDS-MSCs and AML-MSCs did not show macroscopic and/or tumorrelated defects, but both displayed functional features potentially contributing to favor a leukemia-protective milieu.

Keywords: Mesenchymal stromal cells, Acute myeloid leukemia, Myelodysplastic syndrome, Leukemic microenvironment

\section{Background}

Myelodysplastic syndrome (MDS) and acute myeloid leukemia (AML) are two biologically and genetically heterogeneous groups of clonal myeloid neoplastic disorders characterized by hematopoietic stem cell (HSC) dysregulation and ineffective hematopoiesis $[1,2]$. In particular, MDS carries a substantial risk of progressing into AML, although the molecular mechanism underlying this transformation remains unknown. Neoplastic cells derived from the majority of MDS and AML patients harbor cytogenetic and molecular abnormalities thought to account for the outgrowth and differentiation defects of these cells and ultimately for disease pathogenesis $[1,2]$. However, recent evidence implies that the pathogenesis of these and other hematological malignancies depends not only on cell intrinsic factors, but is also supported by the bone marrow (BM) microenvironment in general, and specifically by mesenchymal stromal cells (MSCs). MSCs provide a substantial contribution to the creation of a hematopoietic niche [3, 4], and play an essential role in normal hematopoiesis by regulating HSC proliferation and differentiation. In the last few years, it has been demonstrated that specific changes in MSCs can initiate leukemia in mice [5-7]. This evidence in murine models has provided the rationale to explore the biological and functional features of human MSCs in hematological patients. It was consequently shown that, in various hematopoietic disorders, MSCs presented alterations in the expression of cell adhesion molecules and cytokines, and had an impaired immunosuppressive efficiency and/or a reduced capacity to proliferate or to support hematopoiesis [8-14]. However, so far, data regarding MSC alterations and their contribution to AML and MDS disease mechanisms and/or treatment outcomes have been controversial. In particular, the characterization of AML patient-derived MSCs has been poor and not conclusive, likely due to the high level of disease heterogeneity and to the limited cohort of analyzed patients [15-17]. Although two studies have recently characterized a more robust cohort of MSCs isolated from AML patients, even establishing a link between MSC alterations and treatment outcome [18, 19], a potentially causative or supporting role of MSCs in AML has still not been adequately explored [20]. On the contrary, evidence has accumulated strongly arguing in favor of an MSC contribution to disease pathogenesis in MDS [21]. Indeed, BM samples derived from MDS patients are very challenging to engraft in murine models or fail to confer their MDS clinical phenotype [22, 23], suggesting a permissive role of the microenvironment in MDS. In this study, we investigated and compared MSCs isolated from healthy donors, MDS subjects, and AML subjects in terms of different biological parameters with the aim of highlighting phenotypic and functional alterations and shared features.

\section{Methods}

\section{Patients and healthy controls}

BM samples were obtained from 32 AML patients (18 males, 14 females; median age 60.5 years) and 26 MDS patients (17 males, 9 females; median age 78 years). In addition, BM from 12 healthy donors (HDs) (9 males, 3 females; median age 42 years) was used as the control (see Table 1).

\section{MSC isolation and culture}

BM-derived MSCs were isolated from BM aspirates of HDs (HD-MSCs) or patients affected by acute myeloid leukemia (AML-MSCs) or myelodysplastic syndrome (MDS-MSCs) at diagnosis, and were expanded ex vivo as previously described [24]. Briefly, the mononuclear cell (MNC) fraction was separated by centrifugation over a Ficoll-Paque gradient (Lympholyte CL5020 1.077 g/ml; Cedarlane), resuspended in proliferation medium consisting of low-glucose Dulbecco's modified Eagle's medium (DMEM; Lonza), 10\% fetal bovine serum (FBS; Thermo Fisher Scientific), $2 \mathrm{mM}$ L-glutamine, and 1\% penicillin/streptomycin (pen/strep) (MP Biomedicals), and plated at an initial seeding density of $1.6 \times 10^{5}$ cells/ $\mathrm{cm}^{2}$. After 2-3 days, the nonadherent cell fraction was removed by rinsing cells with phosphate-buffered saline solution (PBS), and monolayers of adherent cells were cultured until they reached $70-80 \%$ confluence. Cells were then detached by trypsin solution ( $0.25 \%$ trypsin/ $0.1 \%$ EDTA in PBS w/o calcium w/o magnesium w/ Phenol Red) (Aurogene, Rome, Italy), reseeded at a density of $3.5 \times 10^{3} \mathrm{cells} / \mathrm{cm}^{2}$, and used for experiments within passages $3-5$. Cell growth was analyzed by direct cell counts at each passage.

\section{Immunophenotype}

For immunophenotype studies, dual-color immunofluorescence was performed using the following panel of phycoerythrin (PE)-conjugated or fluorescein isothiocyanate (FITC)-conjugated monoclonal antibodies: anti-human CD13, anti-human CD19, anti-human CD34, anti-human HLA-DR, anti-human CD44, anti-human CD45, anti-human 


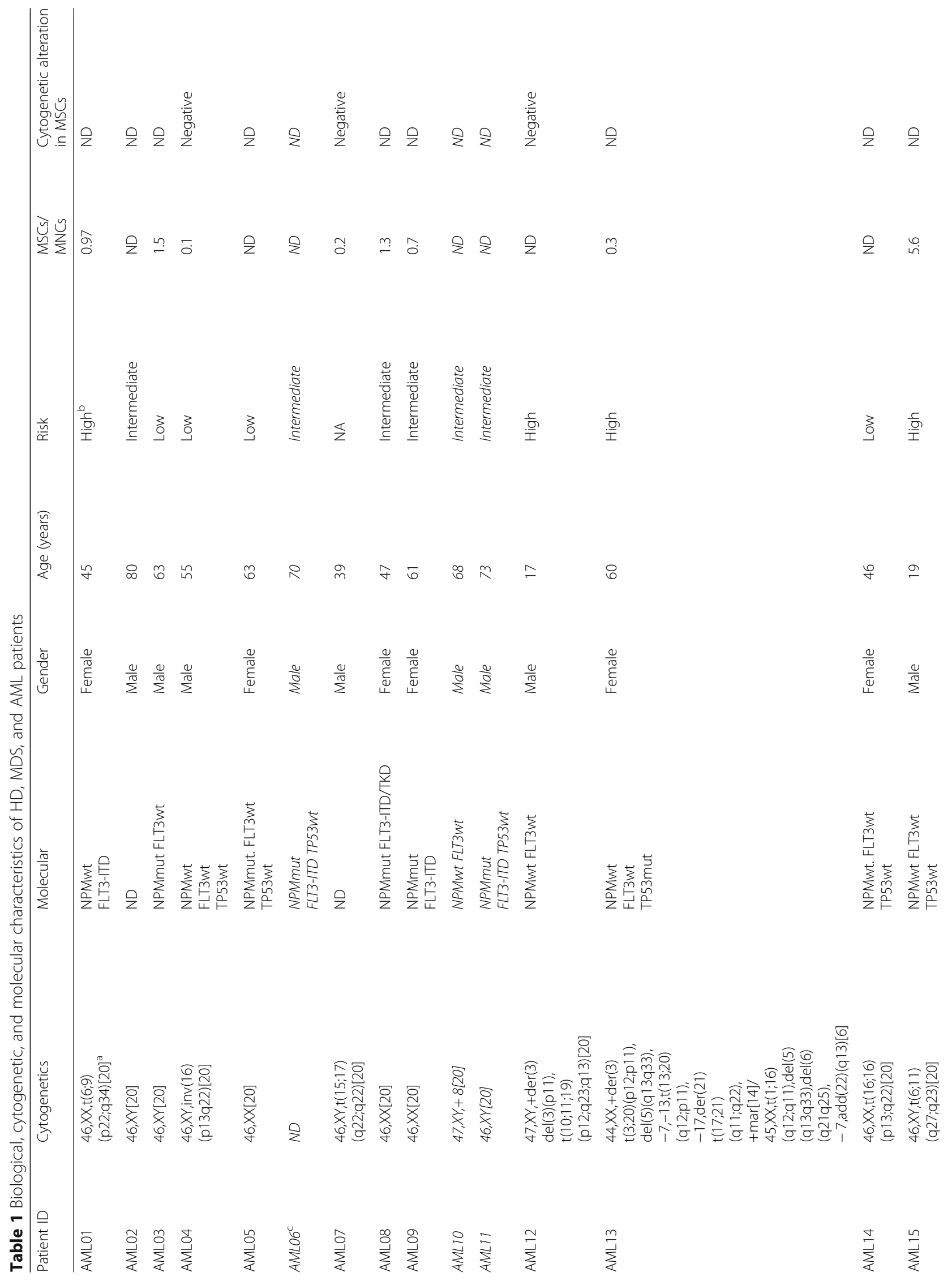




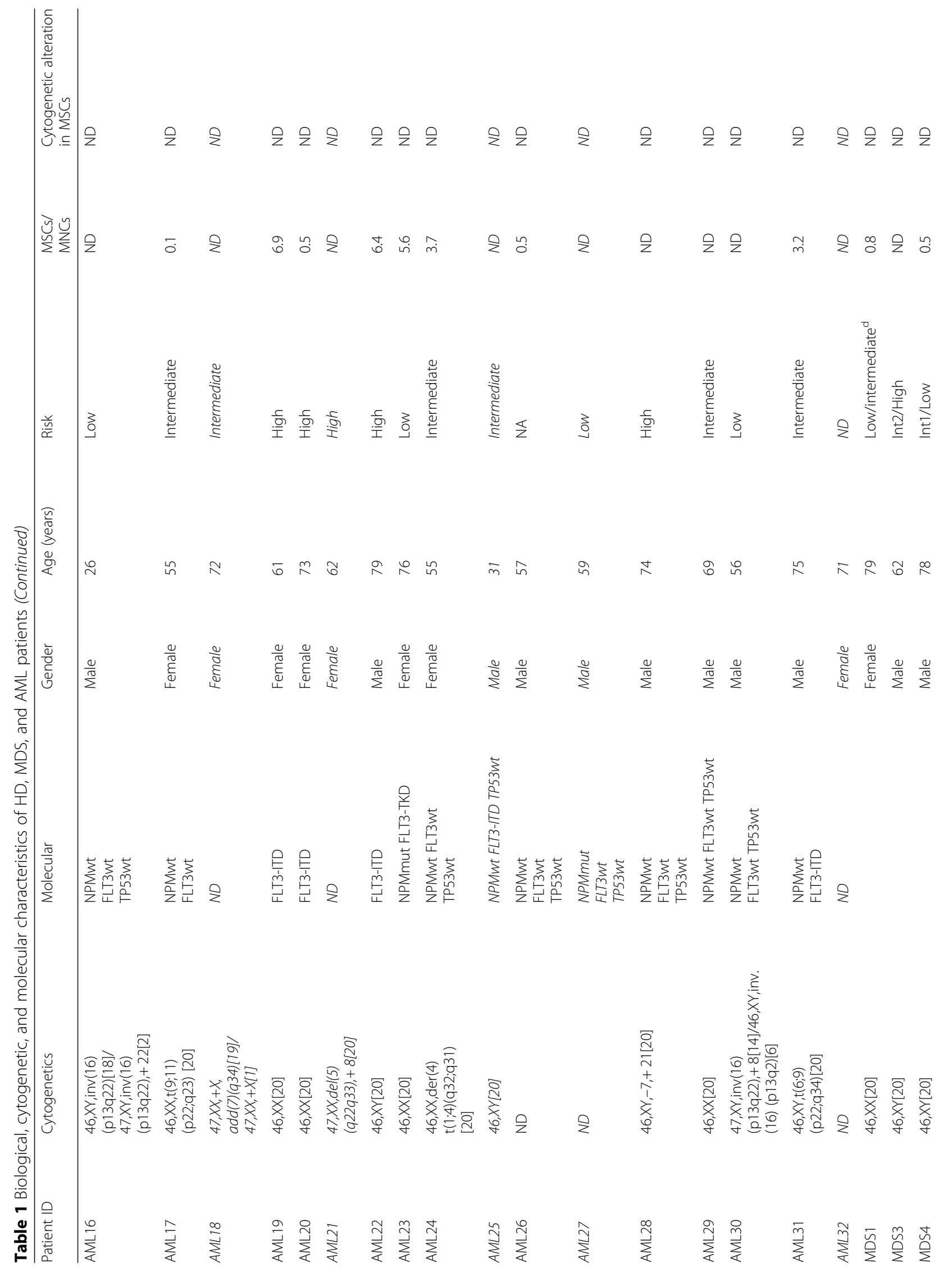




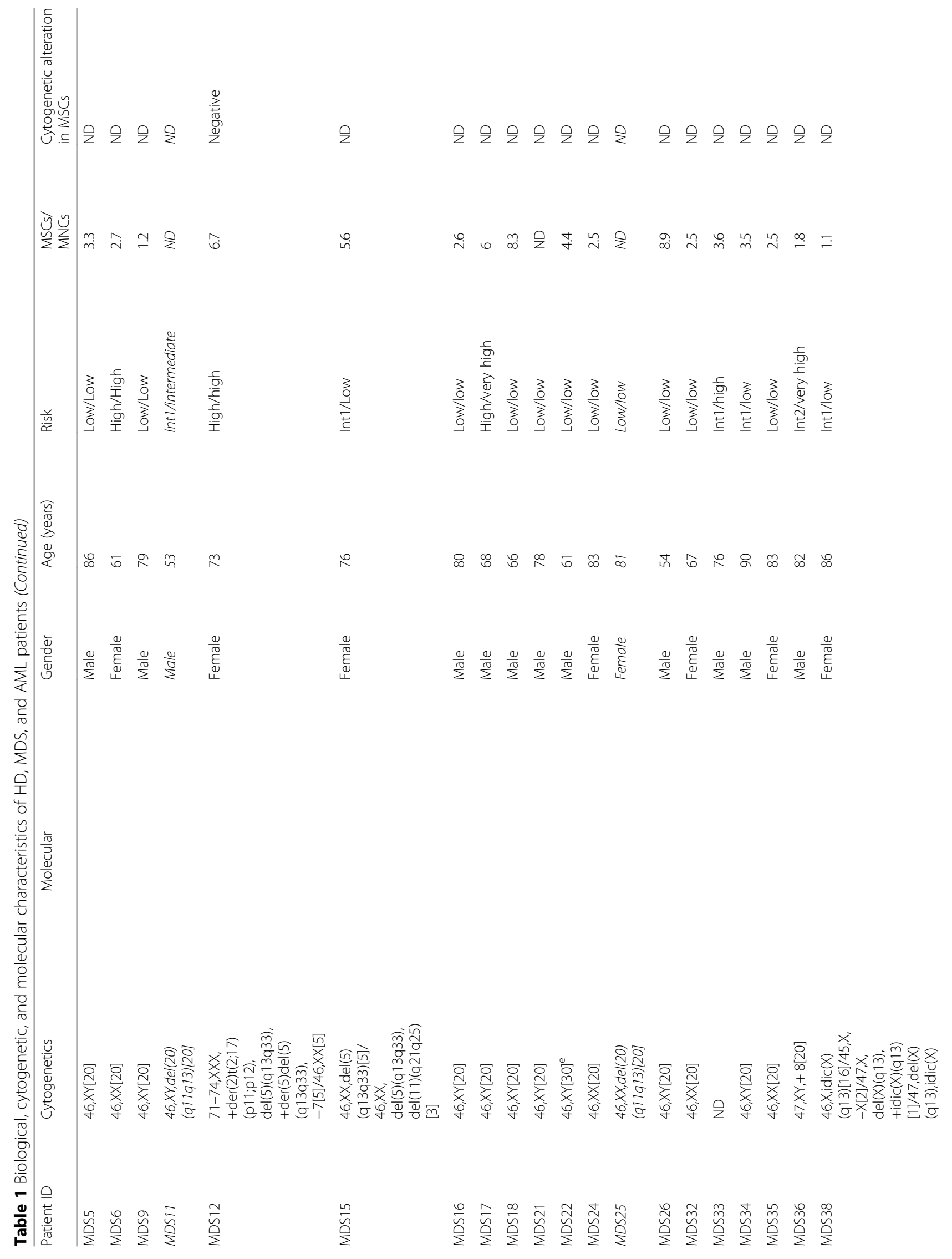




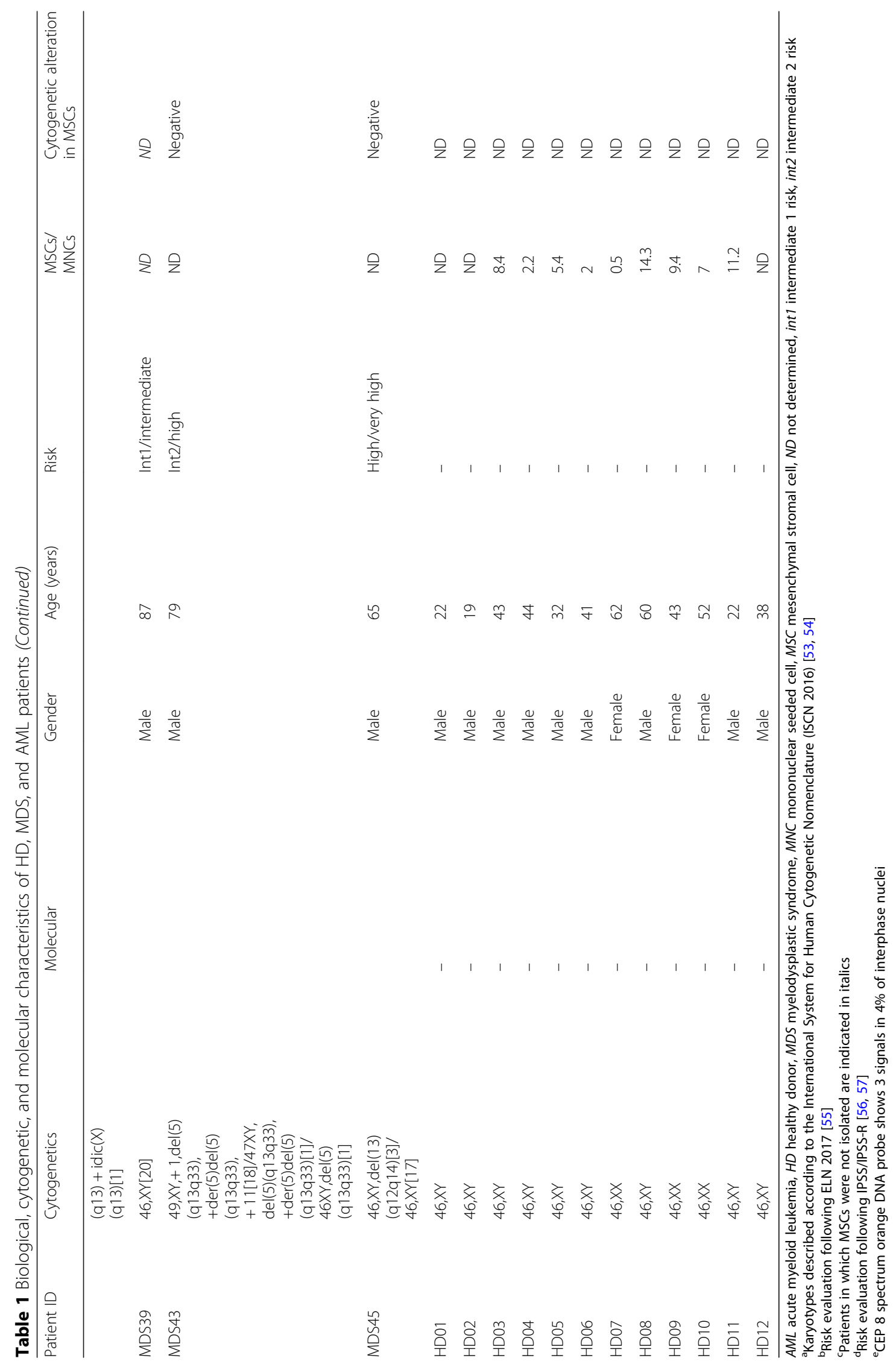


CD73 (Becton Dickinson), anti-human CD14, anti-human CD29, anti-human CD105 (Biolegend), and anti-human CD90 (Chemicon). The cell autofluorescence level was used as the negative control. For cell-surface staining, $1 \times 10^{5}$ cells were incubated, in the presence of the antibodies listed, in $\mathrm{PBS} / 0.5 \% \mathrm{FBS}$ at room temperature with light protection for $15 \mathrm{~min}$. Cells were rinsed in PBS and analyzed by flow cytometry (FACScanto II equipment; Becton Dickinson). A minimum of 10,000 events was collected in list mode on FACSDiva software.

\section{Differentiation potential}

To induce osteogenic differentiation, MSCs were seeded at $3.1 \times 10^{3}$ cells $/ \mathrm{cm}^{2}$ and grown in osteogenic differentiation medium (Lonza) containing L-glutamine, mesenchymal cell growth serum MCGS, dexamethasone, ascorbate, $\beta$-glycerophosphate, and pen/strep. The medium was replaced every 3-4 days. Cell cultures were stopped at day 21 for histological staining and total RNA extraction. Calcium deposition was determined using Alizarin red staining as previously described [24]. Briefly, cells were fixed in 10\% paraformaldehyde (PFA) in PBS at room temperature for $15 \mathrm{~min}$, and rinsed with PBS and distilled water. Fixed cultures were stained with $40 \mathrm{mM}$ Alizarin red solution (Sigma Aldrich), $\mathrm{pH} 4.2$, with gentle shaking at room temperature for $75 \mathrm{~min}$ and rinsed with distilled water. To induce adipogenic differentiation, MSCs were seeded at $2.1 \times 10^{4}$ cells $/ \mathrm{cm}^{2}$ on a Lab-Tek II coverglass chamber (Nalge-Nunc) and grown for 3 days in adipogenic induction medium (Lonza) containing additional h-insulin, L-glutamine, MCGS, dexamethasone, indomethacin, 3-isobuty-1-methyl-xanthine, and pen/ strep followed by 3 days in adipogenic maintenance medium containing h-insulin, L-glutamine, MCGS, and pen/strep. Both steps were repeated up to day 18 when cell cultures were stopped for histological staining and total RNA extraction. Fat droplets within adipogenic differentiated cells were identified using the Oil Red O staining method as previously described [24]. Briefly, cells were fixed in 10\% PFA in PBS at room temperature for $1 \mathrm{~h}$ and rinsed in 60\% isopropanol. The isopropanol was removed and the wells were completely dried and stained with $0.6 \%(w / v)$ Oil Red O solution (Sigma Aldrich) with gentle shaking at room temperature for 15 min. Images were collected with an Axiovert 40 CFL microscope (Carl Zeiss Microscopy).

\section{Total RNA extraction, reverse transcription, and quantitative real-time polymerase chain reaction}

Total RNA was isolated using an RNeasy Micro Kit (Qiagen) according to the manufacturer's instructions and quantified by NanoDrop ND-1000 spectrophotometer (NanoDrop Technologies). For cDNA synthesis, $1 \mu \mathrm{g}$ of denatured total RNA was reverse transcribed using an Improm II kit (Promega) and random hexamers
(Promega) in a $20 \mu \mathrm{l}$ final volume according to the manufacturer's instruction. Quantitative real-time polymerase chain reaction (qRT-PCR) was performed using the ABI-PRISM 7900 Sequence Detection System (Applied Biosystems). The qRT-PCR reactions were performed using a 96-well Optical Reaction Plate. For each PCR run, $1 \mu \mathrm{l}$ of cDNA product was mixed with $2 \times$ Platinum Super mix (Thermo Fisher Scientific) in a total volume of $25 \mu \mathrm{l}$. The thermal cycling conditions consisted of an initial stage of $50{ }^{\circ} \mathrm{C}$ for $2 \mathrm{~min}$, and $95{ }^{\circ} \mathrm{C}$ for $10 \mathrm{~min}, 40$ cycles of melting at $95{ }^{\circ} \mathrm{C}$ for $15 \mathrm{~s}$, and annealing and elongation at $60{ }^{\circ} \mathrm{C}$ for $1 \mathrm{~min}$. Threshold cycle $\left(\mathrm{C}_{\mathrm{t}}\right)$ values for differentiation specific genes (i.e., peroxisome proliferator activated receptor gamma (PPARY), Runt-related transcription factor (RUNX) 2) and an endogenous reference gene (i.e., glyceraldehyde 3-phosphate dehydrogenase (GAPDH)) were determined automatically using the 7900 ABI PRISM system (Applied Biosystems). Relative quantification was calculated using the $\Delta C_{t}$ comparative method [25]. Briefly, the relative level of a specific cDNA was calculated by subtracting the $C_{t}$ value of the endogenous reference gene from the $C_{t}$ value of the specific gene. PPAR $\gamma$ or RUNX2 cDNA levels in undifferentiated cells were taken as 1 . In some experiments, cDNA synthetized as already described from a Universal RNA (Agilent genomics) was used as the reference value and taken as 1 . All reactions were performed in duplicate. Primer probes for PPAR $\gamma, \quad H s 01115513 \_m 1, \quad$ RUNX2, Hs00231692_m1, GAPDH, and Hs00266705_g1 were purchased from Applied Biosystems.

\section{Fluorescent in-situ hybridization}

Molecular cytogenetic analysis was performed on BM-derived AML or MDS cells and BM-derived MSCs isolated as already described. All cells were treated with hypotonic solution and fixed with methanol-acetic acid solution (3:1). Fluorescent in-situ hybridization (FISH) was carried out on fixed cells according to the manufacturer's instructions with appropriate specific probes. The following commercially avaialble probes were used for MSC analysis: EGR1 FISH Probe Kit, LSI MLL Dual Colour, Break Apart Rearrangements Probe and LSI PML/ RAR $\alpha$ Dual Colour, and Dual Fusion Translocation Probe Kit (Vysis); and CBFß/MYH11 Translocation, Dual Fusion Probe, and RB1 Deletion Probe (Cytocell). Images were analyzed using a fluorescence microscope NIKON E1000 equipped with FITC/TRITC/AQUA/DAPI filter sets and the Genikon imaging system software (Nikon Instruments). At least 200 nuclei were counted for each sample.

\section{Coculture experiments}

MSCs were seeded at the density of 20,000 cells $/ \mathrm{cm}^{2}$ and after $24 \mathrm{~h}$ AML cells were seeded with transwells on MSC layers (1:10). After 4 days of cocultures, AML cells 
were harvested and analyzed by flow cytometry. In apoptosis experiments, after 4 days of cocultures, AML cells were harvested and labeled with annexin- $\mathrm{V} /$ propidium iodide (PI) (annexin-V-FLUOS-kit; Roche). Briefly, cells were washed in PBS and then incubated with Annexin-V-FLUOS/PI incubation buffer with light protection at room temperature for $15 \mathrm{~min}$ and analyzed by flow cytometry as already described.

In proliferation experiments, before seeding, AML cells were labeled with carboxyfluorescein succinimidyl ester (CFSE) (BioLegend). Briefly, cells were washed twice in PBS and incubated with CFSE $(5 \mu \mathrm{M})$ with light protection at room temperature for $4 \mathrm{~min}$. Cells were then washed twice in cold medium (RPMI, Lonza) and analyzed by flow cytometry as already described.

\section{In-vitro Treg induction}

MSCs derived from HDs, AML patients, or MDS patients were cocultured for 7 days in autologous RPMI with allogeneic peripheral blood mononuclear cells (PBMCs) (ratio 10:1). After 7 days, PBMCs were harvested and stained using the intracellular staining kit FOXP-3/Transcription Factor Buffer Set (eBioscience/ Thermo Fisher Scientific) including the monoclonal antibodies (mAbs) PE-conjugated anti-human FOXP3 (clone PCH101; Thermo Fisher Scientific), APC-H7-conjugated CD3 (clone SK7; BD/Pharmingen), FITC-conjugated CD4 (clone RPA-T4; Thermo Fisher Scientific), and APC-conjugated CD25 (clone BC96; eBioscience/Thermo Fisher Scientific). For each sample, isotype-matched irrelevant $\mathrm{mAb}$ staining was used as the control. At least 10,000 events were analyzed by flow cytometry as already described. $\mathrm{FoxP}^{+} / \mathrm{CD}^{+} / \mathrm{CD} 25^{+}$ cells were gated on $\mathrm{CD} 4^{+}$cells.

\section{Data analysis}

Data are presented as mean \pm SEM of at least three independent determinations. Statistical differences between groups were determined by Student's $t$ test or one-way analysis of variance (ANOVA) followed by Bonferroni's post-hoc test for multiple comparison. All analyses were performed using GraphPad Prism software (version 6.0). Differences were considered statistically significant at $p$ $<0.05$.

\section{Results}

\section{MDS-MSCs and AML-MSCs show a reduced proliferative} capacity

We isolated and expanded MDS-MSCs $(N=26)$ and AML-MSCs $(N=32)$ at diagnosis from treatment-free patients to rule out potential bias due to chemotherapy effects. As a control, MSCs were isolated and expanded from healthy subjects (HD-MSCs, $N=12$ ). MSCs were successfully obtained from all samples of HDs and from almost all the MDSs (88.5\%, 23 out of 26), while only $75 \%$ (24 out of 32 ) of the AML samples were able to generate MSCs (Table 1). Furthermore, as shown in Fig. 1a, we calculated the number of MSCs isolated after the first passage (P1) normalized to the number of BM-isolated mononuclear seeded cells (MNCs). Although there was, as expected, some variability within each group, we found that this ratio (i.e., the frequency of rescued MSCs) was significantly lower in the AML group than in the HD group $(P<0.01)$, while the MDS-MSC frequency had an intermediate value $(P<$ 0.05 vs HD; not significant vs AML) (Fig. 1a). This suggested that a reduced number of MSC precursors may inhabit the BM of MDS and AML patients. Despite the differences in the isolation efficiency, MSCs were all plastic adherent and showed a typical fibroblastoid elongated shape with no obvious differences between groups (Fig. 1b). In order to compare proliferative capacity, MSCs isolated from the three groups were plated and cultured in the same conditions until confluence. Direct cell counts were determined at each passage from P1 to P5. We observed that the number of HD-MSCs consistently increased at each passage while the number of MDS-MSCs and AML-MSCs slightly rose at the first passage and then remained more or less unchanged $(P<$ 0.001 at P5). This pattern was particularly exacerbated in the MDS-MSCs (Fig. 1c). These data suggested that AML-MSCs and especially MDS-MSCs presented some intrinsic growing defect.

\section{MDS-MSCs and AML-MSCs show typical MSC features}

MSCs isolated as already described were expanded and analyzed at P3 or P4 to ascertain typical biological properties according to the minimal criteria to define "bona fide" MSCs derived from BM [26]. The immunophenotype of MSCs was therefore first characterized by flow cytometry. We found that both MDS-MSCs and AML-MSCs expressed typical MSC markers and were negative for hematopoietic markers in a comparable way to HD-MSCs (Fig. 2a). Some variability existed in MDS-MSCs in the expression levels of CD105 and CD73, but these differences were not statistically significant (Fig. 2a). Thus, these data indicated that both MDS-MSCs and AML-MSCs showed the proper MSC immunophenotype.

Next, we examined the differentiation capacity of MSCs isolated from MDS and AML patients, in comparison with MSCs isolated from HDs. Thus, MSCs were induced to differentiate versus the osteogenic or adipogenic lineage, as described in Methods, and analyzed after 3 weeks by differentiation-specific histological staining. As shown in Fig. 2b, we observed a significant and specific Alizarin red (top) and Oil Red O (bottom) positive staining, respectively, in osteogenic-differentiated and adipogenic-differentiated 

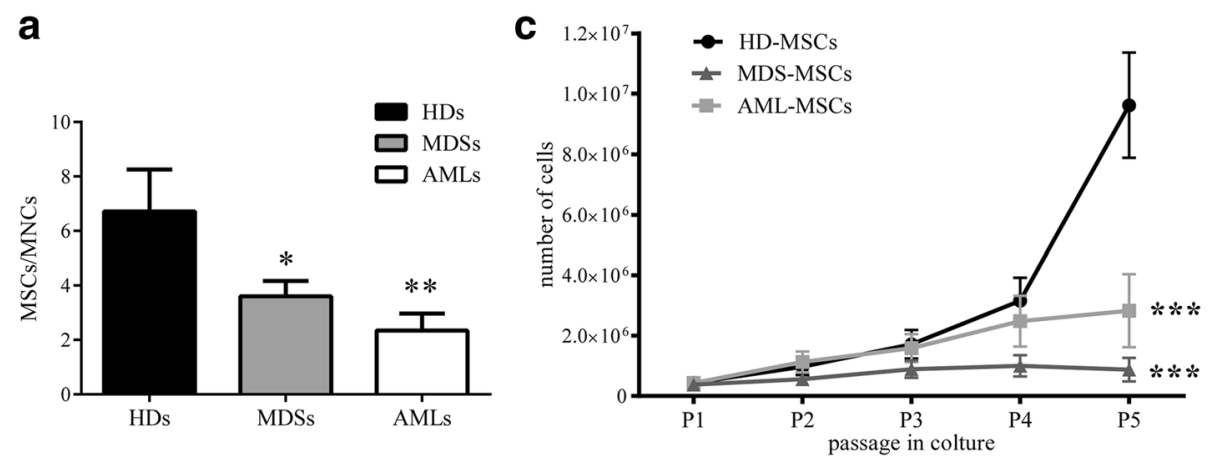

\section{b}
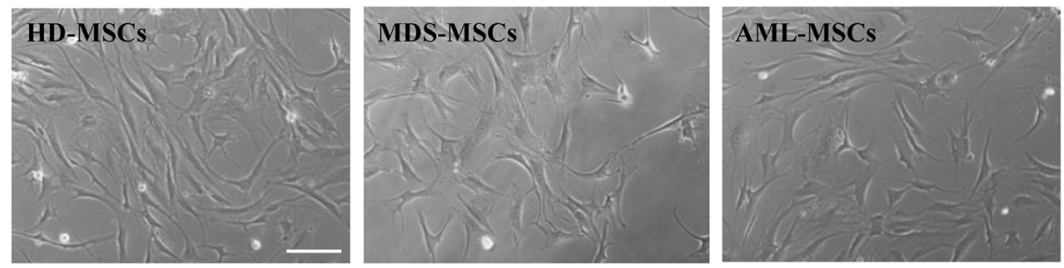

Fig. 1 MSCs derived from MDS and AML patients show normal morphology but reduced proliferative capacity. a MSCs isolated at P1 normalized to number of BM-derived mononuclear cells seeded in three analyzed groups. Results expressed as mean \pm SEM calculated from data obtained from independent samples of HDs $(N=9)$, MDS patients $(N=19)$, AML patients $(N=16)\left(* P<0.05\right.$; $\left.{ }^{* *} P<0.01\right)$. b Representative field of exponential growing culture of HD-MSCs, MDS-MSCs, and AML-MSCs. Magnification 10x; scale bar, 100 um. c Comparison of cell counts in BM-derived HD-MSCs, MDS-MSCs, and AML-MSCs at each passage. Results expressed as mean \pm SEM calculated from data obtained from at least seven independent samples (***P $<0.001$ at P5). MSC mesenchymal stromal cell, MNC mononuclear cell, HD-MSC mesenchymal stromal cell from healthy donor, MDS-MSC mesenchymal stromal cell from myelodysplastic syndrome patient, AML-MSC mesenchymal stromal cell from acute myeloid leukemia patient, P cell culture passage

MSC cultures. However, no significant differences were detected in the intensity of differentiation-specific staining in MDS-MSCs and AML-MSCs in comparison with the staining in HD-MSCs. Differentiation-specific staining was not observed in MSCs of the three groups cultured without differentiation-inducing agents (data not shown). To better quantify the differentiation efficiency, we quantitatively evaluated the expression of osteogenic and adipogenic pivotal transcription factors, before and after MSC differentiation induction, by quantitative real-time-PCR (qRT-PCR). We found that, as expected, RUNX2 and PPAR $\gamma$ expression levels were effectively increased in differentiated MSCs, but no significant differences in induction level were detected between the HD, AML, and MDS groups (Fig. 2c). We also evaluated the expression levels of differentiation master genes in MDS-MSCs and AML-MSCs under nondifferentiating culture conditions and did not find any significant differences (data not shown). These data demonstrate that MDS-MSCs and AML-MDSs presented a normal and comparable differentiation capacity.

\section{MDS-MSCs and AML-MSCs do not harbor tumor-specific cytogenetic abnormalities}

$\mathrm{BM}$ cells derived from hematological patients present, in most cases, tumor-specific genetic alterations. Thus, we decided to use FISH analysis to genetically characterize freshly isolated MNCs and MSCs, obtained as already described, in parallel from the BM of the same AML or MDS patient. As shown in Table 1, most of our patients (10 out of 24 AML patients and 16 out of 23 MDS patients) did not show cytogenetic defects in MNCs, so they were not suitable for FISH analysis on MSCs. In the analyzed samples ( $N=3 \mathrm{MDS}, N=3 \mathrm{AML}$ ), we found that neither MDS-MSCs nor AML-MSCs presented the same chromosomal alterations, typical of myeloid malignancies, as those detected in MNCs at diagnosis (Fig. 3).

\section{MDS-MSCs and AML-MSCs equally support leukemic cell viability and proliferation}

It has been shown that MSCs favor leukemic cell survival and inhibit apoptosis [27, 28]. We decided to test whether AML-MSCs and MDS-MSCs retained this capacity and if they showed differences among them. To rule out the bias due to the intrinsic variability between MDS-derived and AML-derived cells, AML cells isolated from the same AML samples were seeded onto irradiated HD-MSC, MDS-MSC, or AML-MSC layers and cocultured for 4 days, and then apoptosis was evaluated through annexin/PI staining by flow cytometry. We found that HD-MSCs, MDS-MSCs, and AML-MSCs significantly increased leukemic cell viability with no significant differences between groups (Fig. 4a).

To evaluate MSC capacity to stimulate AML cell proliferation, MSC/AML cell coculture experiments, similar to the 


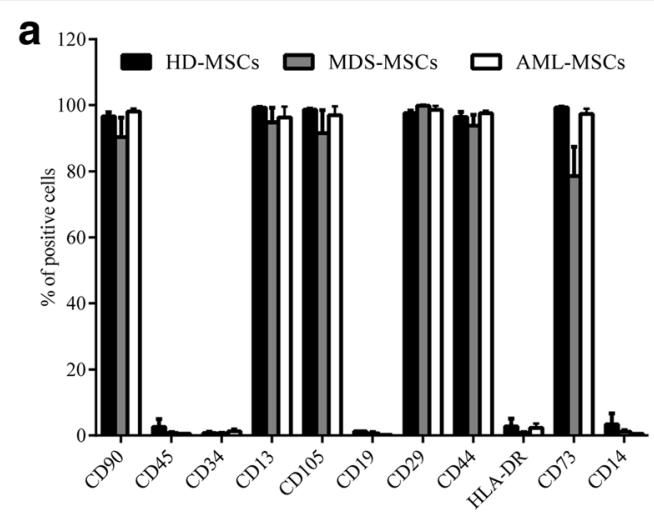

b

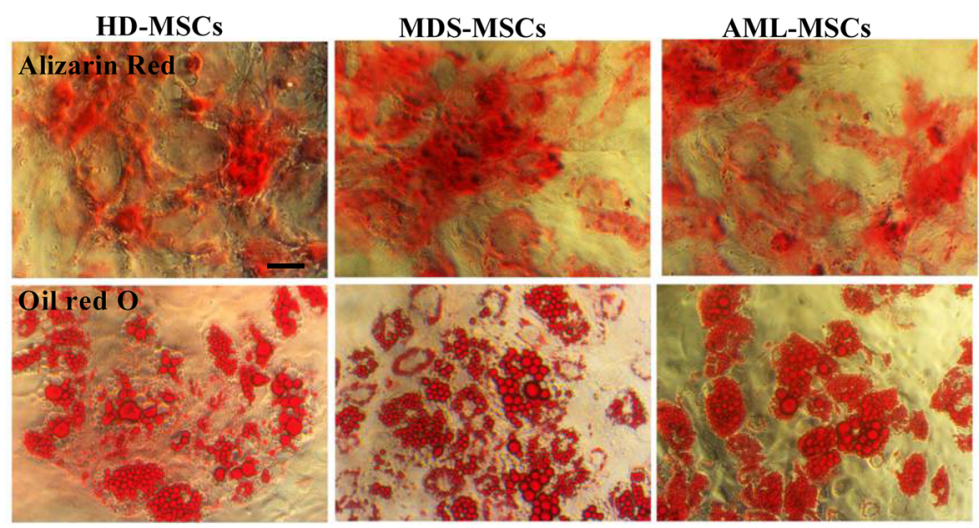

C

Osteogenesis

Adipogenesis
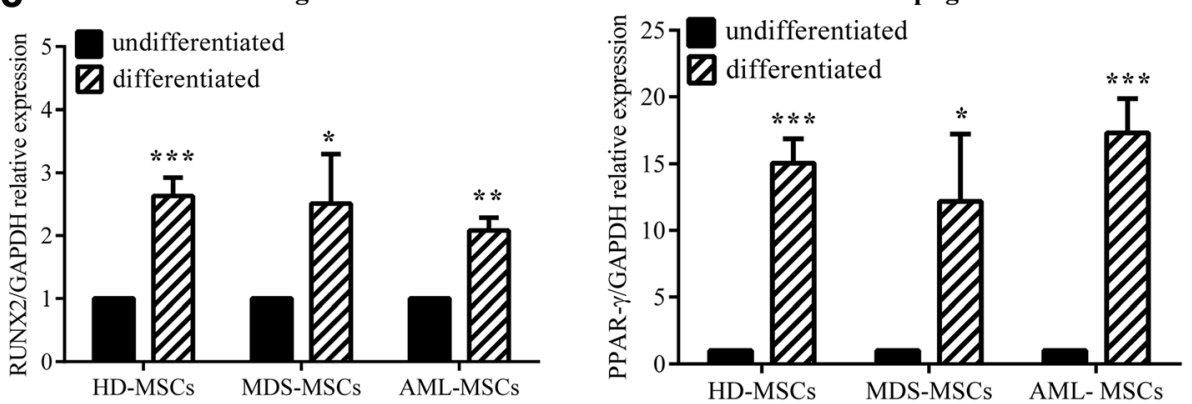

Fig. 2 MDS-MSCS and AML-MSCs show typical MSC biological properties. a Flow cytometry analysis of HD-MSC (N=9), MDS-MSC (N=3), and AML-MSC ( $N=4$ ) immunophenotype. Histograms represent percentage of cells positive for CD90, CD45, CD34, CD13, CD105, CD19, CD29, CD44, CD73, CD14, and HLA-DR. All differences not significant. b Representative microphotographs of Alizarin red (upper row) and Oil Red O (lower row) staining of HD-MSCs, MDS-MSCs, and AML-MSCs cultured for 3 weeks in osteogenic and adipogenic conditions, respectively. Magnification 10x; scale bar, $100 \mu \mathrm{m}$. c qRT-PCR analysis of Runx2 (Runx2/GAPDH relative levels) and PPARY (PPARy/GAPDH relative levels) in undifferentiated (black histograms) and differentiated (crossed histograms) cells following 3 weeks of culture. Expression levels of differentiation specific genes in undifferentiated cells taken as 1 (mean \pm SEM of at least four independent experiments). ${ }^{*} P<0.05 ;{ }^{* *} P<0.01 ;{ }^{* *} P<0.001$. HD-MSC mesenchymal stromal cell from healthy donor, MDS-MSC mesenchymal stromal cell from myelodysplastic syndrome patient, AML-MSC mesenchymal stromal cell from acute myeloid leukemia patient, PPARy peroxisome proliferator activated receptor gamma, RUNX2 Runt-related transcription factor 2, GAPDH glyceraldehyde 3-phosphate dehydrogenase

one already described, were performed with CFSE-labeled AML cells. We found that HD-MSCs, MDS-MSCs, and AML-MSCs slightly but significantly stimulated AML cell proliferation No significant differences were found between groups (Fig. 4b).

\section{MDS-MSCs and AML-MSCs retain the ability to induce} Tregs

In AML, and especially in MDS, immune dysregulation participates in the establishment of a leukemic permissive milieu. We wondered whether there were differences in 


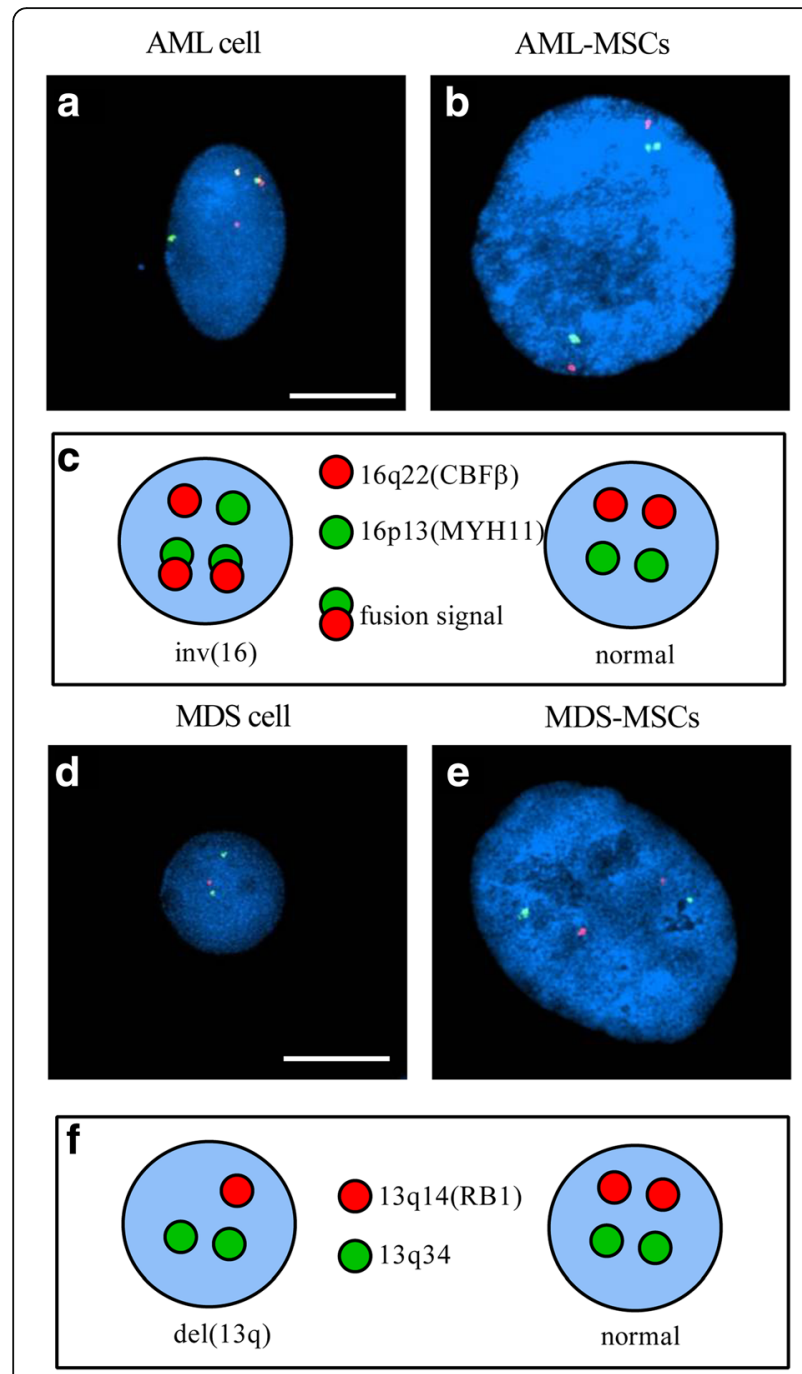

Fig. 3 AML-MSCS and MDS-MSCs do not show tumor-specific chromosomal abnormalities. Representative samples analyzed by fluorescent in-situ hybridization (FISH). CBFB/MYH11 Translocation, Dual Fusion Probe, and RB1 Deletion Probe used to investigate chromosome $16(\mathbf{a}, \mathbf{b})$ and chromosome 13 abnormalities $(\mathbf{c}, \mathbf{d})$, respectively. a BM-derived mononuclear cell with abnormal FISH pattern isolated from an AML patient. b MSC with normal FISH pattern isolated from same AML patient. c Schematic illustration of FISH probes and FISH signal pattern (d). BM-derived mononuclear cell with abnormal FISH pattern isolated from an MDS patient. e MSC with normal FISH pattern isolated from same MDS patient. f Schematic illustration of FISH probes and FISH signal pattern. Magnification (100x). Scale bar $10 \mu \mathrm{m}$. MDS-MSC mesenchymal stromal cell from myelodysplastic syndrome patient, AML-MSC mesenchymal stromal cell from acute myeloid leukemia patient

the immune-regulatory functions of HD-MSCs, MDS-MSCs, and AML-MSCs. In particular, we investigated the ability of MDS and AML patient-derived MSCs to induce $\mathrm{CD}^{+} / \mathrm{CD}^{2} 5^{+} / \mathrm{FoxP}^{+}$cells, that is, regulatory $\mathrm{T}$ cells (Tregs), which are known to suppress immunity also in hematological malignancies [29]. We therefore cocultured HD-MSCs, MDS-MSCs, and AML-MSCs with a

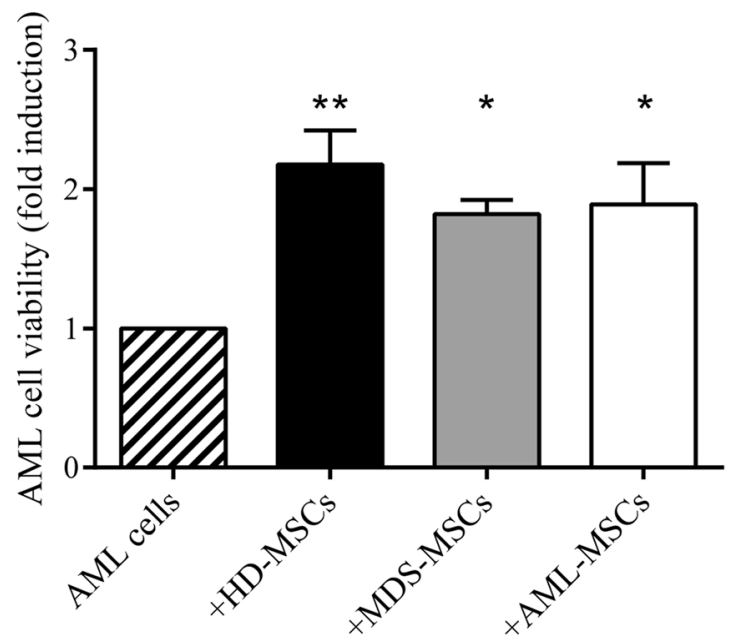

b

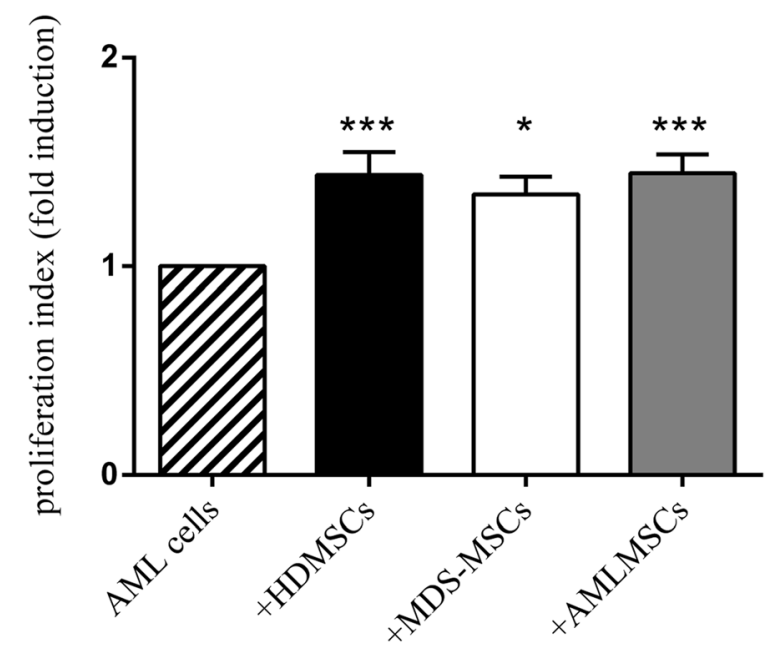

Fig. 4 Cocultures with HD-MSCs, MDS-MSCs, and AML-MSCs increase AML cell viability and proliferation. a Viability rate established by evaluating double-negative cells in flow cytometer analysis of annexin/PI double-stained cells. Viability of AML cells cultured alone considered 1 (fold induction) (mean \pm SEM of at least five independent experiments). ${ }^{*} P<0.05$; ${ }^{* *} P<0.01 \mathrm{Vs} \mathrm{AML}$ cells alone. Differences are not significant between MSC groups. b Cell proliferation of AML cells labeled with CFSE analyzed by flow cytometry. Proliferation rate evaluated taking proliferation of AML cell cultured alone as 1 (fold induction) (mean \pm SEM of at least three independent experiments). ${ }^{*} P<0.05 ;{ }^{* *} P<0.001$ vs AML cells alone. Differences not significant between MSC groups. HD-MSC mesenchymal stromal cell from healthy donor, MDS-MSC mesenchymal stromal cell from myelodysplastic syndrome patient, AML-MSC mesenchymal stromal cell from acute myeloid leukemia patient

allogeneic PBMCs and, after 7 days, we evaluated the generated Tregs (i.e., $\mathrm{CD}^{+} / \mathrm{CD} 25^{+} / \mathrm{FoxP}^{+}$cells). We demonstrated that MDS-MSCs and AML-MSCs efficiently induced Tregs with no significant differences between 
them or versus HD-MSCs (Fig. 5). Thus, our data suggested that MDS-MSCs and AML-MSCs showed a comparable Treg-promoting activity.

\section{Discussion}

In the last few years, the possible contribution of BM-MSCs to the pathogenetic/pathophysiologic process of MDS and AML has gained increasing interest. However, so far, understanding of the MSC role in supporting leukemia in vivo has been hindered by a low level of characterization and conflicting results. In particular, it has not been completely clarified whether AML-MSCs and MDS-MSCs share common features contributing to a disease-permissive microenvironment and preferentially supporting neoplastic cells.

In this study, we characterized and compared MSCs derived from MDS and AML patients with MSCs derived from HDs as a reference control. We showed that both MDS-derived and AML-derived MSCs met the MSC criteria proposed by the International Society for Cellular Therapy [26] and are similar in terms of phenotype and differentiation capacity. However, some functional differences can be underlined. We were unable to isolate MSCs from a substantial fraction of AML patients (25\%, 8 out of 32$)$, while almost all HD and MDS samples yielded MSCs. We did not find a correlation between this issue and a defined cytogenetic/molecular subgroup or patient age (see Table 1). We could hypothesize that a low number of precursors are present

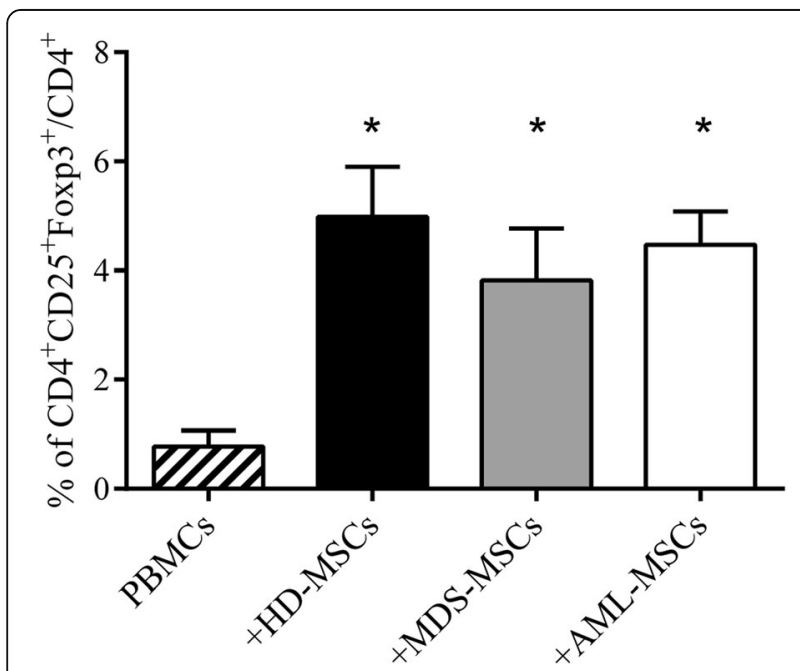

Fig. 5 MDS-MSCs and AML-MSCS induce Tregs similar to HD-MSCs. Graph represents percentage of $\mathrm{CD}^{+} / \mathrm{CD} 25^{+} / \mathrm{FoxP}^{+}$cells analyzed by flow cytometry with respect to percentage of $\mathrm{CD}^{+}$cells. Tregs induced by PBMCs alone used as control (mean \pm SEM of four independent experiments). ${ }^{*} P<0.05$ vs PBMCs alone. Differences not significant between MSC groups. PBMC peripheral blood mononuclear cell, HD-MSC mesenchymal stromal cell from healthy donor, MDS-MSC mesenchymal stromal cell from myelodysplastic syndrome patient, AML-MSC mesenchymal stromal cell from acute myeloid leukemia patient in the $\mathrm{BM}$ of these patients. Indeed, when we compared the frequency of rescued MSCs (i.e., the number of MSCs isolated at P1 normalized to the number of $\mathrm{BM}$-isolated MNCs) we found that this ratio was significantly lower in the AML group than in the HD group, while MSC rescue in MDS has an intermediate value. We could therefore speculate that the reduced number of MSC precursors negatively impacted on MSC recovery and thus, below a given threshold, we were unable to isolate MSCs.

The main abnormality we detected in MDS-MSCs was a marked decrease in their proliferation potential. The growth pattern of MSCs isolated from MDS patients has been questioned, with some authors showing a reduced expansion potential [30-32], and others recording a proliferation rate similar to that of HD-MSCs [33-35]. We found that MDS-MSCs showed a proliferative capacity significantly lower in comparison to that of HD-MSCs. The proliferation rate of MDS-MSCs was also lower than AML-MSCs, albeit not significantly. Some authors showed that the growing defect in MSCs isolated from MDS patients was associated with cell senescence [36, 37]. However, we did not detect alterations in the MDS-MSC morphology, suggesting ongoing senescence. Rather, our unpublished data indicated that fetal bovine serum supplementation partially rescued MDS-MSC proliferation capacity, suggesting that MDS-MSCs displayed an intrinsic proliferation signaling defect, making them more dependent on growth factors.

It is noteworthy that, as expected, MDS samples in our study showed a higher median age than that of AML and HD samples. This could be relevant in differentiation assay results. Indeed, it was reported that MSC osteogenic and adipogenic potential decreased during aging [38-40]. However, we found that HD-MSC, MDS-MSC, and AML-MSC differentiation ability was maintained unchanged, regardless of the median age of the subjects. Indeed, we obtained similar results by comparing samples of similar age (data not shown). Some authors reported that MDS-derived MSCs displayed defective osteogenic and adipogenic lineage priming under nondifferentiating culture conditions [41]. However, when we evaluated the expression levels of differentiation master genes in MDS-MSCs and AML-MSCs under nondifferentiating culture conditions, we did not find significant differences (data not shown).

Some authors suggested that genetic alterations in MSCs might represent a specific mechanism of leukemogenesis. Indeed, they showed that MDS and AML patients, with genetic abnormalities in their in-vitro expanded MSCs, had a worse overall and disease-free survival than the normal karyotype [42]. However, others reported that, in spite of harboring severe chromosomal alterations, MSCs maintained normal functional properties [43]. The majority of 
patients analyzed in this study had a normal karyotype (see Table 1). Thus, FISH was performed in MDS and AML cases where an abnormality was found in neoplastic cells at diagnosis. In these cases, MSCs did not harbor the same cytogenetic abnormalities present in neoplastic cells. Although we could not rule out that MSCs presented genetic mutations different from their hematopoietic counterpart, we could conclude that, in our experience, neither MDS-MSCs nor AML-MSCs shared a common precursor with the original malignant clone. Our data are in agreement with a previous paper in which none of the $28 \mathrm{AML}$ analyzed samples harbored tumor-specific cytogenetic alterations [19]. FISH data in MDS in the literature confirmed that cytogenetic aberrations in MDS-MSCs, if present, differed from chromosomal markers in altered hematopoietic cells [30, 33, 42].

MSCs have a unique immune-regulatory and immunosuppressive ability. Since aberrant immune responses have been associated with the pathophysiology of AML, and especially of MDS, we decided to test the immune-modulatory properties of MDS-MSCs and AML-MSCs. In particular, we decided to investigate the ability of MDS and AML patient-derived MSCs to induce Tregs. Indeed, Tregs have been recognized as essential contributors in microenvironment immunomodulation and ultimately in helping leukemic cells to evade immune surveillance [29, 44]. In the tumor microenvironment, Tregs interact with diverse cell subsets, including MSCs, able to enhance their suppressive function $[45,46]$. Previous studies on this issue are limited and controversial [32, 47, 48]. Our data showed that MDS-MSCs and AML-MSCs were able to induce Tregs with an efficiency comparable to that of HD-MSCs. Moreover, our unpublished results indicate that, like HD-MSCs, MDS-MSCs and AML-MSCs expressed low basal levels of indoleamine 2,3 deoxygenase (IDO)-1 enzyme, which plays an important role in Treg modulation. MDS-MSCs and AML-MSCs also upregulated IDO1 following proinflammatory cytokine treatment to a similar extent with respect to HD-MSCs (our unpublished data). Thus, our data suggest that MDS-MSCs and AML MSCs showed comparable immunoregulatory functions.

It has been demonstrated that MDS-MSCs are defective in hematopoiesis supporting functions [37, 49, 50], while conflicting results have been obtained in AML-MSCs [18, 51, 52]. Murine transplant experiments elegantly demonstrated that neoplastic cells shared the BM milieu with their nonneoplastic counterpart, so that leukemic cells competed with normal HSCs for occupancy of the same protective niche [52]. In this paper, we demonstrated that MDS-MSCs supported AML cell viability and proliferation in vitro as well as HD-MSCs and AML-MSCs. Since MSC aging-which, as expected, occurs in most MDS cases-negatively impacted on hematopoiesis, we could speculate that the MSC capacity to sustain leukemic cell viability and proliferation in vitro together with the impaired hematopoiesissupporting ability, particularly in MDS-MSCs, could virtually contribute to favor a disease-permissive niche.

\section{Conclusions}

Our data demonstrate that MDS-MSCs and AML-MSCs share common features such as phenotype, differentiation capacity, absence of leukemia-specific genetic abnormalities, ability to sustain AML cell viability, and immune-regulatory capacity in vitro. However, AMLMSCs were more difficult to isolate from BM, while MDS-MSCs showed a lower proliferation potential. Overall, MDS-MSCs and AML-MSCs did not present macroscopic defects and/or abnormalities directly related to leukemia, but both displayed functional differences that, translated in vivo, could potentially help to turn the BM microenvironment from hostile to supportive for leukemic cells.

\section{Abbreviations}

AML: Acute myeloid leukemia; AML-MSC: MSC isolated from acute myeloid leukemia patients; BM: Bone marrow; CFSE: Carboxyfluorescein succinimidyl ester; DMEM: Dulbecco's modified Eagle's medium; FBS: Fetal bovine serum; FISH: Fluorescence in situ hybridization; FITC: Fluorescein isothiocyanate; GAPDH: Glyceraldehyde 3-phosphate dehydrogenase; HD: Healthy donor; HD-MSC: MSC isolated from healthy donors; HSC: Hematopoietic stem cell; MCGS: Mesenchymal cell growth serum; MDS: Myelodysplastic syndrome; MDS-MSC: MSC isolated from myelodysplastic syndrome patients; MNC: Mononuclear seeded cell; MSC: Mesenchymal stromal cell; PBMC: Peripheral blood mononuclear cell; PBS: Phosphate-buffered saline solution; PE: Phycoerythrin; PFA: Paraformaldehyde; PPARy: Peroxisome proliferator activated receptor gamma; qRT-PCR: Quantitative real-time polymerase chain reaction; RUNX2: Runt-related transcription factor 2;

Treg: Regulatory T cell

\section{Funding}

The research was supported by Regione Emilia-Romagna and University of Bologna (Young Researcher's Fund of the Regione Emilia Romagna, Bando Alessandro Liberati to AC), FATRO/Foundation Corrado and Bruno Maria Zaini-Bologna, Fabbri1905 and Bologna AlL (Associazione Italiana contro le Leucemie)/Section of Bologna. MC was supported by the University of Bologna (Alma Idea Junior Grant 2017) and the American Society of Hematology (ASH)/Giuseppe Bigi Memorial Award.

\section{Availability of data and materials}

The details of the data used and analyzed for the current study are available from the corresponding author on reasonable request.

\section{Authors' contributions}

GC performed cell culture, molecular experiments, flow cytometry experiments, and statistical analysis. CB performed cytogenetic analysis. DO performed flow cytometry experiments. GM collected the patient data. SP collected patient data. NT participated in study design and coordination. CF collected the patient data and participated in study design and coordination. MC participated in study design and coordination. AC conceived the study, participated in its design and coordination, and helped to draft the manuscript. MC conceived the study, participated in its design and coordination, and drafted the manuscript. All authors read and approved the final manuscript.

Ethics approval and consent to participate

This study was approved by the Ethics Committee of Azienda OspedalieroUniversitaria Policlinico S. Orsola-Malpighi of Bologna (94/2016/O/Tess) and it 
was conducted in accordance with the Declaration of Helsinki. Each sample was processed upon signed informed consent.

\section{Consent for publication \\ Not applicable.}

\section{Competing interests}

The authors declare that they have no competing interests.

\section{Publisher's Note}

Springer Nature remains neutral with regard to jurisdictional claims in published maps and institutional affiliations.

Received: 11 July 2018 Revised: 11 September 2018 Accepted: 20 September 2018 Published online: 25 October 2018

\section{References}

1. Ades L, Itzykson R, Fenaux P. Myelodysplastic syndromes. Lancet. 2014;383: 2239-52.

2. Estey E, Dohner H. Acute myeloid leukaemia. Lancet. 2006;368:1894-907.

3. Frenette PS, Pinho S, Lucas D, Scheiermann C. Mesenchymal stem cell: keystone of the hematopoietic stem cell niche and a stepping-stone for regenerative medicine. Annu Rev Immunol. 2013:31:285-316.

4. Mendez-Ferrer S, Michurina TV, Ferraro F, Mazloom AR, Macarthur BD, Lira $S A$, et al. Mesenchymal and haematopoietic stem cells form a unique bone marrow niche. Nature. 2010;466:829-34.

5. Walkley CR, Olsen GH, Dworkin S, Fabb SA, Swann J, McArthur GA, et al. A microenvironment-induced myeloproliferative syndrome caused by retinoic acid receptor gamma deficiency. Cell. 2007;129:1097-110.

6. Raaijmakers MH, Mukherjee S, Guo S, Zhang S, Kobayashi T, Schoonmaker $J A$, et al. Bone progenitor dysfunction induces myelodysplasia and secondary leukaemia. Nature. 2010:464:852-7.

7. Wang L, Zhang H, Rodriguez S, Cao L, Parish J, Mumaw C, et al. Notch-dependent repression of miR-155 in the bone marrow niche regulates hematopoiesis in an NF-kB-dependent manner. Cell Stem Cell. 2014:15:51-65.

8. Wallace SR, Oken MM, Lunetta KL, Panoskaltsis-Mortari A, Masellis AM. Abnormalities of bone marrow mesenchymal cells in multiple myeloma patients. Cancer. 2001;91:1219-30.

9. Arnulf B, Lecourt S, Soulier J, Ternaux B, Lacassagne MN, Crinquette A et al. Phenotypic and functional characterization of bone marrow mesenchymal stem cells derived from patients with multiple myeloma. Leukemia. 2007:21:158-63.

10. Corre J, Mahtouk K, Attal M, Gadelorge M, Huynh A, Fleury-Cappellesso S, et al. Bone marrow mesenchymal stem cells are abnormal in multiple myeloma. Leukemia. 2007;21:1079-88.

11. Vicente Lopez A, Vazquez Garcia MN, Melen GJ, Entrena Martinez A, Cubillo Moreno I, Garcia-Castro J, et al. Mesenchymal stromal cells derived from the bone marrow of acute lymphoblastic leukemia patients show altered BMP4 production: correlations with the course of disease. PLoS One. 2014;9: e84496.

12. Conforti A, Biagini S, Del Bufalo F, Sirleto P, Angioni A, Starc N, et al. Biological, functional and genetic characterization of bone marrow-derived mesenchymal stromal cells from pediatric patients affected by acute lymphoblastic leukemia. PLoS One. 2013;8:e76989.

13. Zhao ZG, Liang Y, Li K, Li WM, Li QB, Chen ZC, et al. Phenotypic and functional comparison of mesenchymal stem cells derived from the bone marrow of normal adults and patients with hematologic malignant diseases. Stem Cells Dev. 2007;16:637-48.

14. Sparrow RL, O'Flaherty E, Blanksby TM, Szer J, Van Der Weyden MB. Perturbation in the ability of bone marrow stroma from patients with acute myeloid leukemia but not chronic myeloid leukemia to support normal early hematopoietic progenitor cells. Leuk Res. 1997;21:29-36.

15. Chandran P, Le Y, Li Y, Sabloff M, Mehic J, Rosu-Myles M, et al. Mesenchymal stromal cells from patients with acute myeloid leukemia have altered capacity to expand differentiated hematopoietic progenitors. Leuk Res. 2015:39:486-93.

16. Klopp AH, Gupta A, Spaeth E, Andreeff M, Marini F. Concise review: Dissecting a discrepancy in the literature: do mesenchymal stem cells support or suppress tumor growth? Stem Cells. 2011;29:11-9.
17. von der Heide EK, Neumann M, Vosberg S, James AR, Schroeder MP, OrtizTanchez J, et al. Molecular alterations in bone marrow mesenchymal stromal cells derived from acute myeloid leukemia patients. Leukemia. 2017; 31:1069-78.

18. Geyh S, Rodríguez-Paredes M, Jäger P, Khandanpour C, Cadeddu RP, Gutekunst J, et al. Functional inhibition of mesenchymal stromal cells in acute myeloid leukemia. Leukemia. 2016;30:683-91.

19. Diaz de la Guardia R, Lopez-Millan B, Lavoie JR, Bueno C, Castaño J, GómezCasares $\mathrm{M}$, et al. Detailed characterization of mesenchymal stem/stromal cells from a large cohort of AML patients demonstrates a definitive link to treatment outcomes. Stem Cell Rep. 2017:8:1573-86.

20. Le Y, Fraineau S, Chandran P, Sabloff M, Brand M, Lavoie JR, et al. Adipogenic mesenchymal stromal cells from bone marrow and their hematopoietic supportive role: towards understanding the permissive marrow microenvironment in acute myeloid leukemia. Stem Cell Rev. 2016;12:235-44.

21. Medyouf H, Mossner M, Jann JC, Nolte F, Raffel S, Herrmann C, et al. Myelodysplastic cells in patients reprogram mesenchymal stromal cells to establish a transplantable stem cell niche disease unit. Cell Stem Cell. 2014; 14:824-37.

22. Thanopoulou E, Cashman J, Kakagianne T, Eaves A, Zoumbos N, Eaves C. Engraftment of NOD/SCID-beta2 microglobulin null mice with multilineage neoplastic cells from patients with myelodysplastic syndrome. Blood. 2004; 103:4285-93.

23. Benito Al, Bryant E, Loken MR, Sale GE, Nash RA, John Gass M, et al. NOD/ SCID mice transplanted with marrow from patients with myelodysplastic syndrome (MDS) show long-term propagation of normal but not clonal human precursors. Leuk Res. 2003;27:425-36.

24. Ciciarello M, Zini R, Rossi L, Salvestrini V, Ferrari D, Manfredini R, et al. Extracellular purines promote the differentiation of human bone marrowderived mesenchymal stem cells to the osteogenic and adipogenic lineages. Stem Cells Dev. 2013;22:1097-111.

25. Livak KJ, Schmittgen TD. Analysis of relative gene expression data using real-time quantitative PCR and the 2(-Delta Delta C(T)) method. Methods. 2001:25:402-8.

26. Dominici M, Le Blanc K, Mueller I, Slaper-Cortenbach I, Marini F, Krause D, et al. Minimal criteria for defining multipotent mesenchymal stromal cells. The International Society for Cellular Therapy position statement. Cytotherapy. 2006;8:315-7.

27. Ito S, Barrett AJ, Dutra A, Pak E, Miner S, Keyvanfar K, et al. Long term maintenance of myeloid leukemic stem cells cultured with unrelated human mesenchymal stromal cells. Stem Cell Res. 2015:14:95-104.

28. Nwabo Kamdje AH, Krampera M. Notch signaling in acute lymphoblastic leukemia: any role for stromal microenvironment? Blood. 2011;118:6506-14.

29. Beyer M, Schultze JL. Regulatory T cells in cancer. Blood. 2006;108:804-11.

30. Lopez-Villar O, Garcia JL, Sanchez-Guijo FM, Robledo C, Villaron EM, Hernández-Campo P, et al. Both expanded and uncultured mesenchymal stem cells from MDS patients are genomically abnormal, showing a specific genetic profile for the 5q- syndrome. Leukemia. 2009;23:664-72.

31. Aanei CM, Flandrin P, Eloae FZ, Carasevici E, Guyotat D, Wattel E, et al, Intrinsic growth deficiencies of mesenchymal stromal cells in myelodysplastic syndromes. Stem Cells Dev. 2012;21:1604-15.

32. Klaus M, Stavroulaki E, Kastrinaki MC, Fragioudaki P, Giannikou K, Psyllaki M, et al. Reserves, functional, immunoregulatory, and cytogenetic properties of bone marrow mesenchymal stem cells in patients with myelodysplastic syndromes. Stem Cells Dev. 2010;19:1043-54.

33. Soenen-Cornu V, Tourino C, Bonnet ML, Guillier M, Flamant S, Kotb R, et al. Mesenchymal cells generated from patients with myelodysplastic syndromes are devoid of chromosomal clonal markers and support shortand long-term hematopoiesis in vitro. Oncogene. 2005;24:2441-8.

34. Flores-Figueroa E, Arana-Trejo RM, Gutiérrez-Espíndola G, Pérez-Cabrera A, Mayani H. Mesenchymal stem cells in myelodysplastic syndromes: phenotypic and cytogenetic characterization. Leuk Res. 2005;29:215-24.

35. Zhao Z, Wang Z, Li Q, Li W, You Y, Zou P. The different immunoregulatory functions of mesenchymal stem cells in patients with low-risk or high-risk myelodysplastic syndromes. PLoS One. 2012;7:e45675.

36. Liu Q, Zhu H, Dong J, Li H, Zhang H. Defective proliferative potential of MSCs from pediatric myelodysplastic syndrome patients is associated with cell senescence. Int J Clin Exp Pathol. 2015:8:13059-66.

37. Geyh S, Oz S, Cadeddu RP, Fröbel J, Brückner B, Kündgen A, et al. Insufficient stromal support in MDS results from molecular and functional deficits of mesenchymal stromal cells. Leukemia. 2013;27:1841-51. 
38. Zhou S, Greenberger JS, Epperly MW, Goff JP, Adler C, Leboff MS, et al. Agerelated intrinsic changes in human bone-marrow-derived mesenchymal stem cells and their differentiation to osteoblasts. Aging Cell. 2008;7:335-43.

39. D'Ippolito G, Schiller PC, Ricordi C, Roos BA, Howard GA. Age-related osteogenic potential of mesenchymal stromal stem cells from human vertebral bone marrow. J Bone Miner Res. 1999;14:1115-22.

40. Beane OS, Fonseca VC, Cooper LL, Koren G, Darling EM. Impact of aging on the regenerative properties of bone marrow-, muscle-, and adipose-derived mesenchymal stem/stromal cells. PLoS One. 2014;9:e115963.

41. Pavlaki K, Pontikoglou CG, Demetriadou A, Batsali AK, Damianaki A, Simantirakis $\mathrm{E}$, et al. Impaired proliferative potential of bone marrow mesenchymal stromal cells in patients with myelodysplastic syndromes is associated with abnormal WNT signaling pathway. Stem Cells Dev. 2014;23: 1568-81.

42. Blau O, Baldus CD, Hofmann WK, Thiel G, Nolte F, Burmeister T, et al. Mesenchymal stromal cells of myelodysplastic syndrome and acute myeloid leukemia patients have distinct genetic abnormalities compared with leukemic blasts. Blood. 2011;118:5583-92.

43. Flores-Figueroa E, Montesinos JJ, Flores-Guzmán P, Gutiérrez-Espíndola G, Arana-Trejo RM, Castillo-Medina S, et al. Functional analysis of myelodysplastic syndromes-derived mesenchymal stem cells. Leuk Res. 2008:32:1407-16.

44. Teague RM, Kline J. Immune evasion in acute myeloid leukemia: current concepts and future directions. J Immunother Cancer. 2013;1:13-24.

45. Lindau D, Gielen P, Kroesen M, Wesseling P, Adema GJ. The immunosuppressive tumour network: myeloid-derived suppressor cells, regulatory T cells and natural killer T cells. Immunology. 2013;138:105-15.

46. Aggarwal S, Pittenger MF. Human mesenchymal stem cells modulate allogeneic immune cell responses. Blood. 2005;105:1815-22.

47. Han Q, Sun Z, Liu L, Chen B, Cao Y, Li K, et al. Impairment in immunomodulatory function of Flk1(+)CD31(-)CD34(-) MSCs from MDS-RA patients. Leuk Res. 2007;31:1469-78.

48. Zhi-Gang Z, Wei-Ming L, Zhi-Chao C, Yong Y, Ping Z. Immunosuppressive properties of mesenchymal stem cells derived from bone marrow of patient with hematological malignant diseases. Leuk Lymphoma. 2008;49:2187-95.

49. Zhao ZG, Xu W, Yu HP, Fang BL, Wu SH, Li F, et al. Functional characteristics of mesenchymal stem cells derived from bone marrow of patients with myelodysplastic syndromes. Cancer Lett. 2012;317:136-43.

50. Tennant GB, Walsh V, Truran LN, Edwards P, Mills Kl, Burnett AK Abnormalities of adherent layers grown from bone marrow of patients with myelodysplasia. Br J Haematol. 2000;111:853-62.

51. Desbourdes L, Javary J, Charbonnier T, Ishac N, Bourgeais J, Iltis A, et al. Alteration analysis of bone marrow mesenchymal stromal cells from de novo acute myeloid leukemia patients at diagnosis. Stem Cells Dev. 2017;26:709-22.

52. Boyd AL, Campbell CJ, Hopkins Cl, Fiebig-Comyn A, Russell J, Ulemek J, et al. Niche displacement of human leukemic stem cells uniquely allows their competitive replacement with healthy HSPCs. J Exp Med. 2014;211:1925-35.

53. Stevens-Kroef M, Simons A, Rack K, Hastings RJ. Cytogenetic nomenclature and reporting. Methods Mol Biol. 2017;1541:303-9.

54. McGowan-Jordan J, Simons A, Schmid MI. ISCN 2016: An International System for Human Cytogenomic Nomenclature. Cytogenet Genome Res. 2016.

55. Dohner H, Estey E, Grimwade D, Amadori S, Appelbaum FR, Buchner T, et al. Diagnosis and management of AML in adults: 2017 ELN recommendations from an international expert panel. Blood. 2017;129:424-47.

56. Greenberg PL, Tuechler H, Schanz J, Sanz G, Garcia-Manero G, Sole F, et al. Revised international prognostic scoring system for myelodysplastic syndromes. Blood. 2012;120:2454-65.

57. Greenberg P, Cox C, LeBeau MM, Fenaux P, Morel P, Sanz G, et al. International scoring system for evaluating prognosis in myelodysplastic syndromes. Blood. 1997;89:2079-88.

Ready to submit your research? Choose BMC and benefit from:

- fast, convenient online submission

- thorough peer review by experienced researchers in your field

- rapid publication on acceptance

- support for research data, including large and complex data types

- gold Open Access which fosters wider collaboration and increased citations

- maximum visibility for your research: over $100 \mathrm{M}$ website views per year

At BMC, research is always in progress.

Learn more biomedcentral.com/submissions 